\title{
CHRONIC ADAPTATIONS TO LUNG FUNCTION IN BREATH-HOLD DIVING FISHERMEN
}

\section{CRISTIANE MARIA PINTO DINIZ', TIAGO LOPES FARIAS ${ }^{1}$, MAYANE CARNEIRO ALVES PEREIRA ${ }^{1}$, CAIO BRENO REIS PIRES ${ }^{2}$, LUCIANA SOARES LAGES GONÇALVES ${ }^{3}$, PATRÍCIA CHAVES COERTJENS ${ }^{1}$, and MARCELO COERTJENS ${ }^{1}$}

${ }^{1}$ Federal University of Piauí, Parnaíba, Brazil

Department of Rehabilitation

${ }^{2}$ Saint Edwiges Hospital, Parnaíba, Brazil

Department of Rehabilitation

${ }^{3}$ Saint Edwiges Hospital, Parnaíba, Brazil

Department of Medicine

\begin{abstract}
Objectives: The aim of this study was to verify and analyze the existence of chronic adaptations of lung function in freediving fishermen whose occupation is artisanal fishing. Material and Methods: This was a cross-sectional study involving 11 breath-hold diving fishermen and 10 non-breath-hold diving fishermen (control) from the village of Bitupitá in the municipality of Barroquinha (Ceará - Brazil). Anthropometric measurements, chest and abdominal circumferences as well as spirometric and respiratory muscle strength tests were conducted according to the specifications of the American Thoracic Society/European Respiratory Society (ATS/ERS). In order to compare the measured values versus the predicted values, Student $t$ test was used in the case of parametric test and Wilcoxon test in the case of nonparametric test. To compare the inter-group means Student $t$ test was used for parametric test and Mann-Whitney test for the nonparametric one. The level of significance was set at $\alpha=5 \%$. Results: The forced vital capacity (FVC) $(4.9 \pm 0.61 \mathrm{vs} .4 .3 \pm 0.41)$ and forced expiratory volume in $1 \mathrm{~s}\left(\mathrm{FEV}_{1}\right)(4.0 \pm 0.5 \mathrm{l}$ vs. $3.6 \pm 0.3 \mathrm{l})$ were, respectively, higher in the group of divers compared to the control group $(\mathrm{p} \leq 0.05)$. Furthermore, in the group of free divers, the measured $\mathrm{FVC}, \mathrm{FEV}_{1}$ and $\mathrm{FEV}_{1} / \mathrm{FVC}$ ratios were significantly greater than the predicted ones. No differences were found between the measured respiratory pressures. Conclusions: These results indicate that breath-hold diving seems to produce chronic adaptations of the respiratory system, resulting in elevated lung volumes with no airway obstruction.
\end{abstract}

Key words:

Environment, Immersion, Lung volume measurements, Respiratory function tests, Apnea, Underwater fishing

\section{INTRODUCTION}

Breath-hold diving (also known as free diving and apnea diving) is the oldest known form of diving. Since ancient times, it has been used mainly for commercial and military purposes and, more recently, for sport and leisure [1]. Over the years, overcoming limitations of diving has gained importance with respect to achieving different goals either through obtaining greater depth or extending the length of time in apnea. Commercial divers, for example, in order to reach their professional targets [2] may dive several times a day over few hours, regardless of weather conditions or water temperature.

Received: November 23, 2013. Accepted: February 5, 2014.

Corresponding author: M. Coertjens, Federal University of Piauí, Department of Rehabilitation, Av. São Sebastião, 2819, Reis Velloso, CEP: 64.202-020, Parnaíba, PI, Brasil (e-mail: coertjens@hotmail.com). 
Unlike some birds and mammals, such divers are usually capable of holding their breath only for a few minutes, since they are not adapted to a prolonged aquatic existence with high hydrostatic pressure and oxygen deprivation [3]. Thus, several physiological adaptations resulting from these conditions can be observed. The increased hydrostatic pressure promotes blood redistribution to the central region leading to a consequent increase in the intra-thoracic blood volume and the increased pulmonary artery pressure. In many cases, this may result in immersion-induced pulmonary edema or even fatal accidents, accentuated in cold water due to the peripheral vasoconstriction [4]. Thus, in hyperbaric conditions, the airways may be affected and profound changes in the physiological function of the respiratory system may occur [5].

During breath-hold diving, the duration of the period of apnea is based on the body's tolerance to the decreased $\mathrm{PaO}_{2}$ (arterial oxygen tension) and mainly to the increased $\mathrm{PaCO}_{2}$ (arterial carbon dioxide tension), and in the case of an average individual it ranges from 1- up to 2-minute period [6]. The diving depth is limited by the understanding of Boyle's law, which states that for a given temperature, the product of pressure by volume is always constant. There are, therefore, physical limitations to the accumulation in or diversion of blood to the central region, accompanied by the deformation supported by the chest under hyperbaric conditions [2,7]. Accordingly, three possible outcomes may occur due to the environment in which there is an excessive pressure on the lung and chest during apnea: alveolar collapse with formation of atelectasis, infiltration of liquid from the capillaries into the airways and alveolar space, as well as disruption of the alveolar-capillary membrane with bleeding into the empty spaces. These descriptions of changes in lung function, commonly found in apnea divers, are indicative of pulmonary edema [7].

Although there is no consensus among the experts on this matter [5], there is evidence of the occurrence of chronic changes in lung function in commercial and competitive free divers. Changes in lung volumes have been described showing increased TLC (total lung capacity) and FVC (forced vital capacity) and anomalies in the pattern of expiratory airflow with reduced $\mathrm{FEV}_{1}$ (forced expiratory volume in one second), as well as the $\mathrm{FEV}_{1} / \mathrm{FVC}$ ratio [3,8-12]. Reduction in expiratory flows, seen in divers, suggests the occurrence of disorders in small airways, supporting the assumption of the development of an obstructive disease [13].

However, the so far studies have examined chronic effects of diving on pulmonary function in commercial divers who used the self-contained underwater breathing apparatus - (scuba) diving and apnea for competitive sports. The commercial scuba diver who breathes compressed air in a hyperbaric environment, experiences a different situation from that of a free diver. In the case of sport a free diver performs this activity less frequently and for shorter periods of time when compared to the commercial breathhold diver. With regard to breath-hold diving for commercial purposes, there seems to be a gap in the literature regarding the chronic adaptations of lung function in the individuals who engage in this activity.

In the village of Bitupitá, in the municipality of Barroquinha, on the coast of the state of Ceará (Brazil), there are individuals who perform breath-hold diving as a technique for sea fishing. These fishermen practice this activity for subsistence purposes and for the acquisition of small daily income under unhealthy conditions - without sunscreen, nor an adequate supply of water or food, their only equipment being diving masks. From adolescence to the end of adulthood, these individuals work daily for 5 to $6 \mathrm{~h}$ at depths which may vary from 8 to $15 \mathrm{~m}$ on fixed traps constructed with long poles surrounded by thick nets, called pens, where the fish gets trapped and later captured. Therefore, the aim of this study was to investigate the existence of chronic adaptations to free diving in lung function of the fishermen whose economic activity is artisanal fishing. 


\section{MATERIAL AND METHODS}

\section{Subjects}

A total of 97 individuals, living in a fishing community, were invited to answer a questionnaire adapted from Pereira [14]. Of these individuals, 42 were breath-hold diving fishermen and 55 were non-breath-hold diving fishermen. Based on the analysis of the completed questionnaires, 11 breath-hold diving fishermen and 10 nonbreath-hold diving fishermen who agreed to participate in the data collection procedures, which were conducted at the union of fishermen from the village of Bitupitá, were selected. According to the data provided by the fishermen's union, there are 70 fishermen who perform breath-hold diving at depths between 8 and $15 \mathrm{~m}$.

Thirty one breath-hold diving fishermen and 45 nonbreath-hold diving fishermen were excluded from the study according to the exclusion criteria. Exclusion criteria were: a previous clinical diagnosis of tuberculosis, chronic bronchitis, asthma, restrictive lung disease, pulmonary edema, pulmonary emphysema, individuals who had a respiratory infection in the previous 2 weeks, recent angina and/or hemoptysis, retinal detachment, hypertensive crisis, alcoholism, a history of smoking, illicit drug use and advanced structural changes that could compromise respiratory function, such as, among others, scoliosis and kyphoscoliosis [14]. The selected divers were all males aged between 31 and 49 years with at least 11-year experience of breath-hold diving, who dived to depths of between 8 and $15 \mathrm{~m}$ at least 7 times a week.

\section{Procedures}

The selected subjects were instructed not to drink coffee, tea, or any other type of stimulant $6 \mathrm{~h}$ before the test, not to drink alcohol $4 \mathrm{~h}$ before it and not to eat bulky meals less than $1 \mathrm{~h}$ prior to the test. They were also instructed not to perform any other intense physical activities or exercises in the $48 \mathrm{~h}$ prior to the examinations.
Body height, body mass, and the chest and abdominal circumferences were measured and spirometric and respiratory muscle strength tests were conducted according to the ATS/ERS specifications [15]. The chest and abdominal circumferences were measured at the levels of the axilla, xiphoid process and 12th rib (basal) using a metal tape measure, with the subject standing upright in front of the examiner. At each level, the circumference was measured during maximum inspiration close to the TLC and then, after a maximum expiration close to the RV (residual volume). The difference between the 2 measurements represents the thoracic mobility (TM) for each level (axillary: ATM, xiphoid: XTM and basal: BTM) with each measurement being taken 3 times at each level.

The spirometry test was performed using a portable spirometer (MicroQuark, Cosmed, Rome, Italy) that was manually calibrated using a three-liter syringe, according to the manufacturer's instructions. The evaluated spirometric parameters as well as their predicted values [16] were: FVC, FEV, $\mathrm{FEV}_{1} / \mathrm{FVC}$ ratio, $\mathrm{PEF}$ (peak expiratory flow), and $\mathrm{FEF}_{25-75 \%}$ (forced expiratory flow from $25 \%$ to $75 \%$ of the FVC). The test maneuvers were repeated at least 3 times and the highest value obtained was chosen. Only reproducible tests with less than $5 \%$ of variation were considered. The seated subject was instructed to inhale until TLC and then encouraged to exhale through a nozzle until RV [15]. During all the tests the subjects wore a nose clip.

Respiratory muscle strength was assessed with the aid of a manovacuometer (MVD 300; GlobalMed, Porto Alegre, Brazil). The evaluated parameters were MIP (maximal inspiratory pressure) and MEP (maximal expiratory pressure) expressed in $\mathrm{cm}_{2} \mathrm{O}$. To assess MIP, the subjects were instructed to perform a maximal inspiratory effort from RV while seated and wearing a nose clip. To assess MEP the subjects were instructed to perform a maximal expiratory effort from TLC. All the participants performed at least 3 reproducible maneuvers, each maintained for at least $1.5 \mathrm{~s} \mathrm{[15].}$ For the data analysis, the highest value was registered, 
provided it did not exceed the same subject's second highest value by more than $20 \%$. The obtained values were compared with the standard ones for the Brazilian population, with the result expressed as a percentage (\% MIP and \% MEP), allowing the subjects to be classified as having adequate respiratory muscles, when the MIP and MEP were greater than or equal to $75 \%$ of that predicted for men aged 20 to 80 years according to Neder et al. [17]. Curves and/or inappropriate values obtained in the pulmonary function tests were excluded from the sample.

\section{Ethics}

Each participant gave a written consent before joining the study, and the Institutional Bioethical Committee (no. 0065.0.045.000-11) issued their formal consent, according to the Helsinki Declaration of 1975 as revised in 1983.

\section{Statistics}

The collected data were analyzed using descriptive statistics (mean and standard deviation). The normality and homogeneity of variance were evaluated using the ShapiroWilk (Lilliefors) and Levene tests, respectively $(\mathrm{p}>0.05)$. To compare the measured values versus the predicted ones, Student $t$ test was used for parametric test and Wilcoxon test for nonparametric test. To compare the inter-group means Student $t$ test was used in the case of parametric test and Mann-Whitney test in the case of the nonparametric one. The level of significance was set at $\alpha=5 \%$. The analyses were carried out with the aid of the SPSS vs. 11. 0 .

\section{RESULTS}

All the variables were homogeneous and within normal ranges ( $p>0.05)$, except for the measured and predicted MEP and XTM values in the breath-hold diving group. In these cases, nonparametric tests were performed. In the free-diver group, the mean age, body mass, body height, and body mass index (BMI) were: $38.3 \pm 5.7$ years, $73.3 \pm 8.5 \mathrm{~kg}, 1.68 \pm 0.1$ and $25.9 \pm 2.8$, respectively. In the control group the mean age, body mass, body height,

Table 1. Anthropometrical characteristics of the breath-hold diving fishermen group and the non-breath-hold diving fishermen (control group)

\begin{tabular}{lcccccc}
\hline \multirow{2}{*}{ Parameter } & \multicolumn{3}{c}{$\begin{array}{c}\text { Control group } \\
(\mathrm{N}=10)\end{array}$} & \multicolumn{3}{c}{$\begin{array}{c}\text { Breath-hold diving group } \\
(\mathrm{N}=11)\end{array}$} \\
\cline { 2 - 7 } & $\mathrm{M} \pm \mathrm{SD}$ & $\min$. & $\max$ & $\mathrm{M} \pm \mathrm{SD}$ & $\min$. & $\max$ \\
\hline Age (years) & $41.10 \pm 4.2$ & 32.0 & 46.00 & $38.3 \pm 5.7$ & 31.00 & 49.00 \\
Body mass (kg) & $71.00 \pm 13.6$ & 50.0 & 91.00 & $73.3 \pm 8.5$ & 62.00 & 92.00 \\
Body height (cm) & $1.65 \pm 0.1$ & 1.5 & 1.78 & $1.68 \pm 0.1$ & 1.57 & 1.79 \\
Body mass index & $25.90 \pm 4.4$ & 18.4 & 33.40 & $25.9 \pm 2.8$ & 22.70 & 31.10 \\
\hline
\end{tabular}

$\mathrm{M}$ - mean; SD - standard deviation.

min. - minimal value; max - maximal value.

$\mathrm{p}>0.05$.

Table 2. Lung function characteristics of the breath-hold diving fishermen group and the non-breath-hold diving fishermen (control group)

\begin{tabular}{|c|c|c|c|c|c|c|}
\hline \multirow[t]{2}{*}{ Parameters } & \multicolumn{3}{|c|}{$\begin{array}{l}\text { Control group } \\
(\mathrm{N}=10)\end{array}$} & \multicolumn{3}{|c|}{$\begin{array}{l}\text { Breath-hold diving group } \\
\qquad(\mathrm{N}=11)\end{array}$} \\
\hline & $\mathrm{M} \pm \mathrm{SD}$ & $\min$. & $\max$ & $\mathrm{M} \pm \mathrm{SD}$ & $\min$. & $\max$ \\
\hline \multicolumn{7}{|l|}{ Measured values } \\
\hline $\operatorname{MEP}\left(\mathrm{cm} \mathrm{H}_{2} \mathrm{O}\right)$ & $124.7 \pm 18.0$ & 102.0 & 161.0 & $131.3 \pm 20.0$ & 106.0 & 162.0 \\
\hline $\operatorname{MIP}\left(\mathrm{cm} \mathrm{H}_{2} \mathrm{O}\right)$ & $114.0 \pm 16.1$ & 94.0 & 137.0 & $132.0 \pm 30.0$ & 93.0 & 178.0 \\
\hline FVC (l) & $4.3 \pm 0.4$ & 3.7 & 5.0 & $4.9 \pm 0.6^{* \#}$ & 3.9 & 5.9 \\
\hline
\end{tabular}


Table 2. Lung function characteristics of the breath-hold diving fishermen group and the non-breath-hold diving fishermen (control group) - cont.

\begin{tabular}{|c|c|c|c|c|c|c|}
\hline \multirow[t]{2}{*}{ Parameters } & \multicolumn{3}{|c|}{$\begin{array}{l}\text { Control group } \\
(\mathrm{N}=10)\end{array}$} & \multicolumn{3}{|c|}{$\begin{array}{l}\text { Breath-hold diving group } \\
(\mathrm{N}=11)\end{array}$} \\
\hline & $\mathrm{M} \pm \mathrm{SD}$ & $\min$. & $\max$ & $\mathrm{M} \pm \mathrm{SD}$ & $\min$. & $\max$ \\
\hline$\overline{\mathrm{FEV}_{1}(\mathrm{l})}$ & $3.6 \pm 0.3$ & 3.2 & 4.1 & $4.0 \pm 0.5^{* \#}$ & 3.2 & 4.6 \\
\hline $\mathrm{FEV}_{1} / \mathrm{FVC}(\%)$ & $83.3 \pm 4.0$ & 78.3 & 90.3 & $83.0 \pm 2.8^{*}$ & 78.3 & 87.9 \\
\hline \multicolumn{7}{|l|}{ Predicted values } \\
\hline $\operatorname{MEP}\left(\mathrm{cm} \mathrm{H}_{2} \mathrm{O}\right)$ & $131.6 \pm 3.0$ & 128.0 & 139.4 & $133.0 \pm 8.0$ & 112.1 & 140.2 \\
\hline $\operatorname{MIP}\left(\mathrm{cm} \mathrm{H}_{2} \mathrm{O}\right)$ & $123.2 \pm 4.0$ & 118.5 & 129.7 & $124.6 \pm 4.8$ & 116.1 & 130.5 \\
\hline FVC (l) & $4.0 \pm 0.4$ & 3.1 & 4.6 & $4.4 \pm 0.4$ & 3.5 & 4.8 \\
\hline $\mathrm{FEV}_{1}(\mathrm{l})$ & $3.3 \pm 0.3$ & 2.6 & 3.8 & $3.6 \pm 0.3$ & 2.9 & 4.0 \\
\hline $\mathrm{FEV}_{1} / \mathrm{FVC}(\%)$ & $80.0 \pm 1.0$ & 78.8 & 81.4 & $80.3 \pm 0.9$ & 78.9 & 81.3 \\
\hline
\end{tabular}

MEP - maximal expiratory pressure; MIP - maximal inspiratory pressure (expressed in absolute values); FVC - forced vital capacity; $\mathrm{FEV}_{1}$ - forced expiratory volume in $1 \mathrm{~s} ; \mathrm{FEV}_{1} / \mathrm{FVC}$ - ratio. Other abbreviations as in Table 1.

* Intra-group means comparisons (measured values vs. predicted values) $(\mathrm{p} \leq 0.05)$.

\# Inter-group means comparisons (control group vs. breath-hold diving group) ( $\mathrm{p} \leq 0.05)$.

and BMI were: $41.1 \pm 4.2$ years, $71.0 \pm 13.6 \mathrm{~kg}, 1.65 \pm 0.1$ and 25.9 \pm 4.4 , respectively. Comparing both groups, didn't reveal any statistically significant differences between the means of the variables $(p>0.05)$ (Table 1$)$.

In the breath-hold diving group, the mean TM values were: $4.4 \pm 1.7 \mathrm{~cm}$ for ATM; $4.1 \pm 1.5 \mathrm{~cm}$ for XTM; and $3.5 \pm 1.6 \mathrm{~cm}$ for BTM. In the control group the average was $4.0 \pm 1.5 \mathrm{~cm}$ ATM, $3.7 \pm 1.3 \mathrm{~cm}$ for XTM and $3.2 \pm 1.6 \mathrm{~cm}$ for BTM. There were no statistically significant differences in TM between the groups ( $p>0.05)$. Regarding the spirometry tests, analysis of the FVC and $\mathrm{FEV}_{1}$ showed there were statistically significant differences between the groups ( $\mathrm{p} \leq 0.05$ ). The mean FVC was $4.9 \pm 0.61$ in the free-diving group and $4.3 \pm 0.41$ in the control group, while the mean $\mathrm{FEV}_{1}$ was $4.0 \pm 0.51$ in the free-diving group and $3.6 \pm 0.31$ in the control group (Table 2). There was no significant difference between the groups in terms of the predicted values for the pulmonary function tests $(p>0.05)$. When comparing the measured and the predicted values in the free-diving group, statistically significant differences were found between the means for the $\mathrm{FVC}, \mathrm{FEV}_{1}$ and $\mathrm{FEV}_{1} / \mathrm{FVC}$ ratio $(\mathrm{p} \leq 0.05)$ (Figure 1). The PEF and $\mathrm{FEF}_{25-75 \%}$ variables
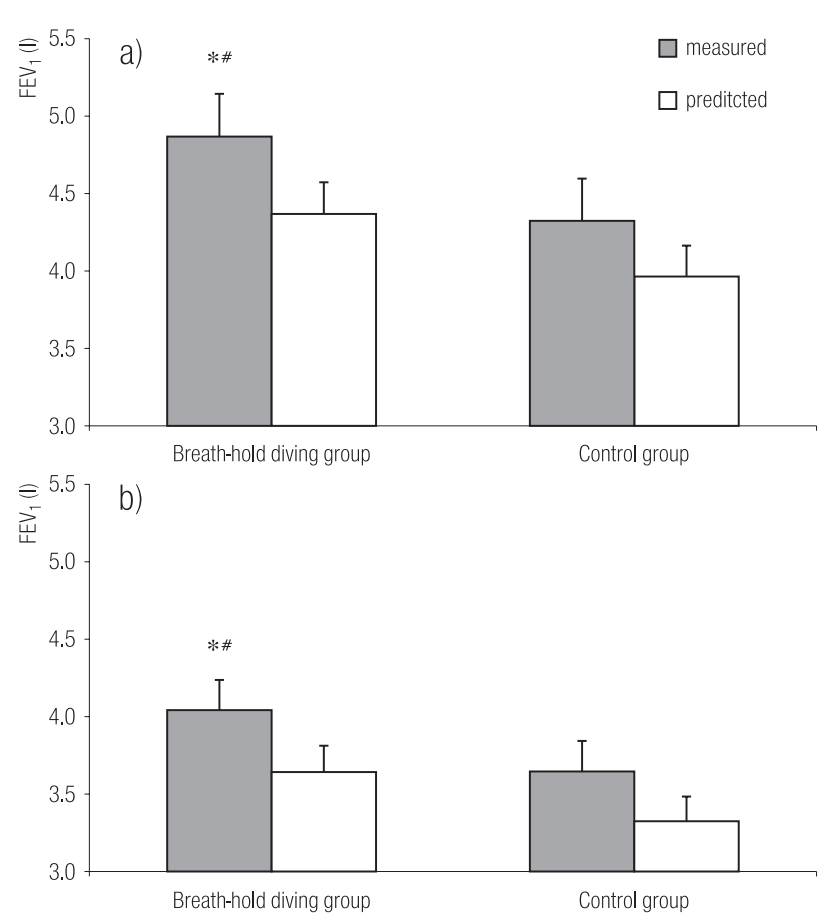

* Intra-group means comparisons.

\# Inter-group means comparisons. $\mathrm{p} \leq 0.05$.

Fig. 1. Measured and predicted values of (a) forced vital capacity $(\mathrm{FVC})$ and (b) forced expiratory volume in $1 \mathrm{~s}\left(\mathrm{FEV}_{1}\right)$ of the breath-hold diving fishermen group and the non-breathhold diving fishermen (control group) 
and the respiratory muscle strength tests showed no significant differences.

In percentage terms, the difference between the measured values and the predicted values (\% predicted) in the freediving group was $100 \%$ for MEP, $106 \%$, for MIP, $112 \%$ for $\mathrm{FVC}, 111 \%$ for $\mathrm{FEV}_{1}$ and $103 \%$ for the $\mathrm{FEV}_{1} / \mathrm{FVC}$ ratio. In the control group the difference was $95 \%$ for MEP, $92 \%$ for MIP, $110 \%$ for FVC, $109 \%$ for $\mathrm{FEV}_{1}$ and $104 \%$ for the $\mathrm{FEV}_{1} / \mathrm{FVC}$ ratio, with no differences found between the groups.

\section{DISCUSSION}

During breath-hold diving, the liquid medium promotes a series of physiological adaptations in humans, which come about due to the physicochemical characteristics of the aquatic environment, such as: higher density, viscosity and specific heat of water [6]. Moreover, the individual is subjected to respiratory deprivation of respiration and the effects of the increased hydrostatic pressure [13]. The magnitude of the physiological adaptations resulting from diving depends mainly on the individual's age and diving experience [7].

Therefore, the effect of physiological adaptations resulting from free diving stand out because there were no statistically significant differences in terms of age or the anthropometric variables (Table 1), which are important factors that could influence lung function [17]. In relation to the measures for maximal respiratory muscle strength, besides sex, the correlation with age, which is used as an independent variable in predictive equations [18], is quite strong. In the case of spirometric volumes, the most important parameters for their evaluation are: body height, age, sex and exposure to tobacco smoke. After sex, body height is the single most important determinant of spirometric function [14].

Another important finding is that no statistically significant differences were found between the groups in relation to the variables predicted from predictive equations for both the respiratory pressure measurements and for spirometry (Table 2). These results highlight the homogenous nature of the groups demonstrating they contain individuals that are similar in age, anthropometric data and respiratory variables.

Although the free divers presented greater measured MIP and MEP values than the control group, the respiratory muscle strength test showed there was no significant difference between the groups. Moreover, their measured values did not differ significantly from the predicted ones. In general, studies suggest that there is no diving effect on maximal respiratory of divers [3]. Tetzllaf et al. [3] found no effect of diving on MIP in their assessment of mechanical characteristics and respiratory function when comparing competitive free divers, scuba divers and controls.

The measured FVC and $\mathrm{FEV}_{1}$ values were significantly higher in the free-diving group compared to the control group (Table 2). In contrast to our results, many researchers have observed a decline in $\mathrm{FEV}_{1}[9,10-12]$ and $\mathrm{FVC}$ in divers $[8,9,11,12]$. Of these studies, only Tetzllaf et al. [3] evaluated pulmonary function in free divers who, because they had competitive goals, dived to depths greater than the subjects in the present study. The other studies evaluated commercial scuba divers breathing a mixture of gases under hyperbaric conditions, a situation quite different from breath-hold diving. All of these studies found a reduction in spirometric volumes, including the $\mathrm{FEV}_{1} / \mathrm{FVC}$ ratio [3], suggesting obstructive defects in pulmonary function developing gradually in divers along with the increasing time of diving practice.

In our study, we found no differences in $\mathrm{FEV}_{1} / \mathrm{FVC}$ ratio and the values were found to be normal, suggesting that the increase in the FVC of the free divers was an offset by an increase in their $\mathrm{FEV}_{1}$. Increases in $\mathrm{FVC}$ and $\mathrm{FEV}_{1}$ have been reported in competitive free divers. However, unlike the subjects in the present study, those individuals were trained in the glossopharyngeal insufflation (GI) technique [19]. 
Furthermore, the $\mathrm{FVC}, \mathrm{FEV}_{1}$ and $\mathrm{FEV}_{1} / \mathrm{FVC}$ ratio measured in the free diving group were significantly higher than the predicted values (Table 2). Similarly to our findings, other studies have also found higher measured FVC $[5,8-10,19]$ and $\mathrm{FEV}_{1}[5,19]$ in divers than those predicted using population data. There is a good correlation between higher measured than predicted FVC and diving depth and length of professional diving career, i.e., the greater the length of time practicing diving and the greater the depth, the greater the difference between the measured values and the predicted values [9]. Although studies indicate that divers have reduced lung function over time, they still have higher FVC than population's values [8-10]. In this sense, in terms of lung volume, breath-hold diving seems to produce a positive adaptation, despite the studies questioning the origin of the large lung volumes found in divers due to selected or chronic exposure to diving [8-10]. Some authors suggest that the increase in lung volume found in competitive free divers may be a result of an increase in the number of alveoli or the alveolar size by the virtue of training [20,21]. Others, have attributed the increase in lung volumes to the improved performance of the respiratory muscles gained from free diving or from GI $[19,22,23]$. This condition may be related to our findings, since the free-diving fishermen, who participated in this study, perform repetitive apneas for three to five hours on a daily basis in hyperbaric conditions at depths ranging from 8 to $15 \mathrm{~m}$ deep according to the tide (Figure 1). Although the place of work of the divers is in hot waters, next to the Equator, we have no evidence that would suggest that the temperature of the water of diving could somewhat influence chronic adaptations verified in pulmonary of these divers. This aspect strengthens the aspects that characterize professional practice of these individuals.

Thus, the main finding of this study is the large lung volume, without any indication of airway obstruction, found in the free diving fishermen compared with their predicted values and to the control group. These results stand out even more because of the similarity found between the ages, anthropometric data and the values for the respiratory muscle strength and spirometric tests predicted for each group. In addition, the predicted percentages for the spirometric variables were greater than $100 \%$ for both groups. This result reinforces outstanding performance in the maneuvers during the spirometric test and excellent lung health of the assessed subjects.

Although the reduced number of individuals evaluated in this work is an important limitation of the study, the sample size was very judicious as it included individuals that could perform in the similar conditions and could provide significant pulmonary adaptations, without the influence of other factors. Beyond that, it is important to highlight the uncommon characteristics of this study sample that are not found in other studies dedicated to the same theme.

In conclusion, the free-diving fishermen exhibit an above average lung function, with increased $\mathrm{FVC}$ and $\mathrm{FEV}_{1}$ without airway obstruction. Thus, one could attribute these results to a selection process that has led such divers to be a part of a group with above average lung volumes or to a process by which lung function is improved by repetitive breath-hold diving at depths of 8 to $15 \mathrm{~m}$.

\section{REFERENCES}

1. Ashcroft FM. Life at the extremes: The science of survival. London: Harper Collins; 2000.

2. Muth CM, Ehrmann U, Radermacher P. Physiological and clinical aspects of apnea diving. Clin Chest Med. 2005;26: 381-94, http://dx.doi.org/10.1016/j.ccm.2005.05.007.

3. Tetzlaff K, Scholz T, Walterspacher S, Muth CM, Metzger J, Roecker K, et al. Characteristics of the respiratory mechanical and muscle function of competitive breath-hold divers. Eur J Appl Physiol. 2008;103:469-75, http://dx.doi.org/10.1007/ s00421-008-0731-9. 
4. Koehle MS, Lepawsky M, Mckenzie DC. Pulmonary oedema of immersion. Sports Med. 2005;35:183-90, http://dx.doi. org/10.2165/00007256-200535030-00001.

5. TetzlaffK, Theysohn J, Stahl C, SchlegelS, Koch A, Muth CM. Decline of $\mathrm{FEV}_{1}$ in scuba divers. Chest. 2006;130:238-43, http://dx.doi.org/10.1378/chest.130.1.238.

6. Pendergast DR, Lundgren CEG. The underwater environment: cardiopulmonary, thermal, and energetic demands. J Appl Physiol. 2009;106:276-83, http://dx.doi.org/10.1152/ japplphysiol.90984.2008.

7. Lindholm P, Lundgren CEG. The physiology and pathophysiology of human breath-hold diving. J Appl Physiol. 2009;106: 284-92, http://dx.doi.org/10.1152/japplphysiol.01127.2007.

8. Crosbie WA, Clarke MB. Physical characteristics and ventilator function of 404 commercial divers working in the North Sea. Br J Ind Med. 1977;34:19-25.

9. Watt SJ. Effect of commercial diving on ventilatory function. Br J Ind Med. 1985;42:59-62.

10. Skogstad M, Thorsen E, Haldorsen T. Lung function over the first 3 years of a professional diving career. Occup Environ Med. 2000;57:390-5, http://dx.doi.org/10.1136/oem.57.6.390.

11. Skogstad M, Thorsen E, Haldorsen T, Kjuus H. Lung function over six years among professional divers. Occup Environ Med. 2002;59:629-33, http://dx.doi.org/10.1136/ oem.59.9.629.

12. Skogstad M, Skare O. Pulmonary function among professional divers over 12 years and the effect of total number do dives. Aviat Space Environ Med. 2008;79:883-7, http:// dx.doi.org/10.3357/ASEM.2333.2008.

13. Dillard T, Khosla S, Ewald FW Jr, Kaleem MA. Pulmonary function testing and extreme environments. Clin Chest Med. 2005;26:485-507, http://dx.doi.org/10.1016/ j.ccm.2005.05.006.
14. Pereira CAC. [Spirometry]. J Pneumol. 2002;28(3):S01-82. Portuguese.

15. American Thoracic Society / European Respiratory Society. Statement on respiratory muscle testing. Am J Respir Crit Care Med. 2002;166:518-624, http://dx.doi.org/10.1164/ rccm.166.4.518.

16. Quanjer PhH. European Respiratory Society. Standardized Lung Function Testing. Eur Respir J. 1993;6(16):3-102s.

17. Neder JA, Andreoni S, Lerario MC, Nery LE. Reference values for lung function tests. II. Maximal respiratory pressures and voluntary ventilation. Braz J Med Biol Res. 1999;32:719-27, http://dx.doi.org/10.1590/S0100879X1999000600007.

18. Evans JA, Whitelaw WA. The assessment of maximal respiratory mouth pressures in adults. Respir Care. 2009;54(10):1348-59.

19. Lemaître F, Clua E, Andréani B, Castres I, Chollet D. Ventilatory function in breath-hold divers: effect of glossopharyngeal insufflation. Eur J Appl Physiol. 2010;108:741-7, http:/ dx.doi.org/10.1007/s00421-009-1277-1.

20. Calder IM, Sweetnham K, Chan KK, Williams MM. Relation of alveolar size to forced vital capacity in professional divers. Br J Ind Med. 1987;44:467-9.

21. Donnelly PM, Grunstein RR, Peat JK, Woolcock AJ, Bye PT. Large lungs and growth hormone: an increased alveolar number? Eur Respir J. 1995;8:938-47.

22. Nygren-Bonnier M, Gullstrand L, Klefbeck B, Lindholm P. Effects of glossopharyngeal pistoning for lung insufflation in elite swimmers. Med Sci Sports Exerc. 2007;39:836-41, http://dx.doi.org/10.1249/mss.0b013e31803191c1.

23. Lemaitre F, Joulia F, Chollet D. Apnea: A new training method in sport? Med Hypotheses. 2010;74:413-5, http:// dx.doi.org/10.1016/j.mehy.2009.09.051.

This work is available in Open Access model and licensed under a Creative Commons Attribution-NonCommercial 3.0 Poland License - http://creativecommons.org/ licenses/by-nc/3.0/pl/deed.en. 